\title{
Protective Effect of Cerium against Salinity-Induced Oxidative Stress in Jerusalem Artichoke (Helianthus tuberosus)
}

\author{
Wenjun $\mathrm{Li}^{1}$, Zhihong Tang ${ }^{2 *}$, Jiasen $\mathrm{Lv}^{2}$, Bao Ju${ }^{2}$, Zhengyi Liu' ${ }^{1}$ and Song Qin ${ }^{1 *}$ \\ ${ }^{1}$ Yantai Institute of Coastal Zone Research, Chinese Academy of Sciences, Yantai 264003, China \\ ${ }^{2}$ College of Life Science, Yantai University, Yantai 264005, China \\ *For correspondence: tangzhihong7405@163.com; sqin@yic.ac.cn
}

\begin{abstract}
The effects of cerium (Ce) on protecting Jerusalem artichoke (Helianthus tuberosus L.) against oxidative stress induced by salinity were studied. Exposure to $\mathrm{NaCl}(150 \mathrm{mM})$ markedly inhibited the growth of $H$. tuberosus seedlings and the inhibition was significantly alleviated by $\mathrm{CeCl}_{3}(0.1 \mathrm{~m} M)$. The result showed that $\mathrm{CeCl}_{3}$ prevented decline in the chlorophyll content induced by salinity. The contents of hydrogen peroxide $\left(\mathrm{H}_{2} \mathrm{O}_{2}\right)$, superoxide radicals $\left(\mathrm{O}_{2} \cdot{ }^{-}\right)$and malondialdehyde (MDA) were increased, which suggested that oxidative stress induced by salinity. Addition with $\mathrm{CeCl}_{3}$ dramatically depressed $\mathrm{H}_{2} \mathrm{O}_{2}, \mathrm{O}_{2}{ }^{-}$ and MDA accumulation caused by salt stress. Furthermore, the activities of superoxide dismutase (SOD), catalase (CAT) and peroxidase (POD) in $H$. tuberosus seedlings under salt stress were also increased. The data suggested that appropriate concentration $\mathrm{CeCl}_{3}$ could protect $H$. tuberosus from salinity-induced oxidative stress by reducing cellular level of ROS directly and by improving antioxidant defense system. (C) 2017 Friends Science Publishers
\end{abstract}

Keywords: Jerusalem artichoke; Cerium; Salinity; Oxidative stress; Antioxidant defense system

\section{Introduction}

Soil salinity influences plant productivity around the globes (Shabala and Cuin, 2008). In plants, salt stress causes adverse effects on energy production, photosynthesis, lipid metabolism and so on (Wu et al., 2014; Kasim et al., 2016; Tabassam et al., 2016). Moreover, salt stress results in oxidative stress by increasing in cellular level of reactive oxygen species (ROS) (Mittler, 2002; Nounjan et al., 2012). These ROS are highly reactive molecules which cause protein denaturation, DNA mutation and lipid peroxidation thereby bringing about cellular damage (Tanou et al., 2009). To alleviate oxidative injury plants have executed different kinds of antioxidant activities including catalase (CAT, EC1.11.1.6), peroxidase (POD, EC 1.11.1.7), superoxide dismutase (SOD, EC 1.15.1.1), glutathione (GSH) and ascorbate (AsA), which have the ability to detoxify ROS (Ashraf and Ali, 2008; Ashraf, 2009; Sergio et al., 2012).

The rare earth elements (REEs) are a set of seventeen trivalent metallic elements (Liu et al., 2012). A large quantity of REEs have entered into the environment and accumulated in the ecosystem. For instance, cerium (Ce) nitrate has been widely used as a microelement fertilizer for improving agricultural productivity in China (Wang et al., 2012; Zhang et al.,
2013). Low concentrations of $\mathrm{Ce}^{3+}$ had positive effects for A. flosaquae. The optimum concentration $\mathrm{Ce}^{3+}$ was $0.1 \mathrm{mg} / \mathrm{L}$. High concentrations of $\mathrm{Ce}^{3+}$ led negtive effects to A. flosaquae. Exposure to high concentrations of $\mathrm{Ce} 3+$ led todecrease of Chla content (Wang et al., 2012). $\mathrm{Ce}^{3+}$ application could reduce ROS and malondialdehyde (MDA) contents and decrease cell membrane permeability of spinach (Liao et al., 1994; Hong et al., 2002). Although numerous physiological effects of cerium on plants have been reported in recent years, the essentiality of cerium on plants exposed to environmental stresses is still largely unknown.

Jerusalem artichoke (Helianthus tuberosus L.) is an economically important crop species (Monti et al., 2005). It is not only as a food for human consumption but also has numerous industrial uses (Long et al., 2008; Huang et al., 2012). Previous research has indicated that a high oxidative damage and suppressed antioxidant defense system of $H$. tuberosus exposed to salt stress (Xue and Liu, 2008). Up to now, there is no information known about the influence of cerium on oxidative stress in this plant under salt stress. In the present study, the effect of cerium on the growth and antioxidative defense system in $H$. tuberosus seedlings exposed to salt stress was investigated. The aim of the present study was to evaluate the role of cerium in the alleviation of negative effects of salinity on $H$. tuberosus seedlings. 


\section{Materials and Methods}

\section{Plants and Treatments}

Jerusalem artichoke (Helianthus tuberosus L.) N1 was selected for this study from Tai'an Blue Source Agricultural Co. Ltd. Shandong province, China. All the experiments were carried out in a greenhouse. The minimum and maximum temperatures were 21 and $31^{\circ} \mathrm{C}$, respectively. Tuber slices with buds of $\mathrm{N} 1$ were sown in 20-mesh quartz sand. After 20 days, uniform size seedlings were planted into $4 \mathrm{~L}$ plastic pots containing quartz sand (Wang et al., 2011a).

Five days later, the plants were divided into five groups as follows: control group (marked as Control), treated with half-strength Hoagland solution; Salt stress group (marked as $\mathrm{NaCl}$ ), treated with $150 \mathrm{mM} \mathrm{NaCl}$ in half-strength Hoagland solution; $\mathrm{CeCl}_{3}$-treated groups (marked as $\mathrm{Ce}$ ), treated with $\mathrm{CeCl}_{3}(0.1 \mathrm{~m} M)$ in half-strength Hoagland solution; $\mathrm{NaCl}$ with supplemental $\mathrm{CeCl}_{3}$ (marked as $\mathrm{Ce}+\mathrm{NaCl}$ ), treated with $\mathrm{CeCl}_{3}(0.1 \mathrm{mM})$ and $\mathrm{NaCl}(150 \mathrm{mM})$ in half-strength Hoagland solution. The treatment concentrations were based on previous studies, in which a number of lower and higher levels of $\mathrm{CeCl}_{3}$ were applied. Plants were harvested for biochemical and physiological analyses after 15 days of treatment.

\section{Plant Growth Measurement}

The height and fresh weights of the plants were recorded. Then a known amount of homogenized samples was incubated in an oven at $70^{\circ} \mathrm{C}$ until there were no further changes and dry mass was determined.

\section{Chlorophyll Contents Measurements}

Total chlorophyll in leaves were extracted and measured according to Wellburn (1994). Chlorophyll was extracted with chilled $80 \%(\mathrm{v} / \mathrm{v})$ acetone in the dark. The extract was centrifuged at 5,000 $\mathrm{g}$ for $5 \mathrm{~min}$ and then the supernatant was analyzed spectrophotometrically at 646 and $663 \mathrm{~nm}$ for chlorophyll.

\section{Assay of $\mathrm{H}_{2} \mathrm{O}_{2}, \mathrm{O}_{2}^{-}$and MDA Levels}

Leaves collected from the plants were homogenized in chilled phosphate buffer (50 $\mathrm{mM}, \mathrm{pH} 7.8)$ containing $1 \%(\mathrm{v} / \mathrm{v})$ polyvinylpyrrolidone, $5 \mathrm{mM}$ ethylenediaminetetraacetic acid and $5 \mathrm{~m} M$ dithiothreitol. The homogenates were centrifuged at $12000 \mathrm{~g}$ for 20 $\min$ at $4^{\circ} \mathrm{C}$ and the supernatants were used for assays of $\mathrm{H}_{2} \mathrm{O}_{2}, \mathrm{O}_{2}{ }^{-}$and MDA levels and enzymatic activities.

$\mathrm{H}_{2} \mathrm{O}_{2}$ content was measured at $390 \mathrm{~nm}$ (Wang et al., 2009). The $\mathrm{O}_{2} \cdot{ }^{-}$was determined at $530 \mathrm{~nm}$ by measuring the content of nitrite (Elstner and Heupel, 1976). Lipid peroxidation was assayed by measuring MDA content using the thiobarbituric acid (TBA) reaction (Buege and Aust, 1978).

\section{Measurements SOD, POD and CAT Activities}

The activity of SOD was assayed by measuring the ability to inhibit photochemical reduction of nitroblue tetrazolium (NBT) (Beauchamp and Fridovich, 1971). One unit of SOD activity was equated to the amount of enzyme required to cause $50 \%$ inhibition in the rate of NBT photo reduction. CAT activity was determined by following the decomposition of $\mathrm{H}_{2} \mathrm{O}_{2}$ at $240 \mathrm{~nm}$ (Durner and Klessing, 1996). $1 \mu M \mathrm{H}_{2} \mathrm{O}_{2}$ decomposed in one minute was equated to one unit of CAT. The activity of POD was assayed by the increase per minute in the absorbance at $470 \mathrm{~nm}$ during the oxidation of guaiacol according to Hammerschmidt et al. (1982). One unit of POD activity was equated to an increase of 0.01 absorbance units per minute.

\section{Statistical Analysis}

The experiments were repeated three times. Based on the appropriate two-way variance analysis (ANOVA) the analysis of variance was computed for statistically significant differences determined. SPSS software (SPSS Inc., version 18.0, Chicago, USA) was used to perform statistical analysis, followed by the Duncan's Multiple Range Test (DMRT). All measured data were expressed as mean \pm SD. Differences between treatment and comparisons with $P<0.05$ were considered as statistical significance.

\section{Results}

\section{Growth of $\boldsymbol{H}$. Tuberosus Plant}

Table 1 shows the plant height, fresh weight and dry weight of $H$. tuberosus seedlings under various conditions. Under $\mathrm{NaCl}(150 \mathrm{mM})$ treatment, the plant height, fresh weight and dry weight were significantly decreased by $45.2,36.8$ and $32.1 \%$, respectively compared to the control seedlings. However, application of $0.1 \mathrm{mM} \mathrm{CeCl}{ }_{3}$ to the saline nutrient solution, the plant height, fresh weight and dry weight were significantly increased by 24.4, 26.9 and $33.8 \%$, respectively. Under normal condition, the application of 0.1 $\mathrm{m} M \mathrm{CeCl}_{3}$ obviously improved the plant height, fresh weight and dry weight of the seedlings.

\section{Chlorophyll Content}

The effects of various treatments on the contents of chlorophyll a (chl-a), chlorophyll b (chl-b) and total chlorophyll are shown in Table 2. When compared with the control group, the $150 \mathrm{~m} M \mathrm{NaCl}$ treatments significantly decreased chl-a, chl-b and total chlorophyll contents by 40.2, 53.8 and $46.3 \%$, respectively. However, $\mathrm{NaCl}$-induced reduction in chl-a, chl-b, total chlorophyll content was alleviated by $0.1 \mathrm{~m} M \mathrm{CeCl}_{3}$ addition, significantly increased them by $43.1,72.2$ and $54.3 \%$. 
Improving Salt Stress by Cerium in Jerusalem Artichoke / Int. J. Agric. Biol., Vol. 19, No. 5, 2017

Table 1: Effect of $\mathrm{CeCl}_{3}$ and $\mathrm{NaCl}$ on growth indexes of H. tuberosus

\begin{tabular}{lllll}
\hline Growth parameters & \multicolumn{3}{c}{ Treatment } & $\mathrm{NaCl}+\mathrm{Ce}$ \\
\cline { 2 - 5 } & Control & $\mathrm{NaCl}$ & $\mathrm{Ce}$ & $7.15 \pm 0.12 \mathrm{c}$ \\
Fresh weight $(\mathrm{g})$ & $10.71 \pm 0.35 \mathrm{ab}$ & $5.08 \pm 0.26 \mathrm{~d}$ & $11.52 \pm 0.39 \mathrm{a}$ & $0.85 \pm 0.17 \mathrm{bc}$ \\
Dry weight $(\mathrm{g})$ & $1.06 \pm 0.07 \mathrm{~b}$ & $0.67 \pm 0.04 \mathrm{~d}$ & $1.21 \pm 0.26 \mathrm{a}$ & $15.53 \pm 0.59 \mathrm{c}$ \\
Plant height $(\mathrm{cm})$ & $19.35 \pm 0.76 \mathrm{ab}$ & $11.61 \pm 0.43 \mathrm{~d}$ & $20.26 \pm 0.85 \mathrm{a}$ & \\
\hline
\end{tabular}

Each value represents the mean $\pm \mathrm{SD}, \mathrm{n}=3$. Different letters within each each column indicate statistically significant differences at $P<0.05$ using Duncan's Multiple Range Test (DMRT)

Table 2: Effect of $\mathrm{CeCl}_{3}$ and $\mathrm{NaCl}$ on chlorophyll contents of $H$. tuberosus

\begin{tabular}{|c|c|c|c|c|}
\hline \multirow[t]{2}{*}{ Chlorophylls } & \multicolumn{4}{|c|}{ Treatment } \\
\hline & Control & $\mathrm{NaCl}$ & $\mathrm{Ce}$ & $\mathrm{NaCl}+\mathrm{Ce}$ \\
\hline chl-a content $\left(\mathrm{mg} \mathrm{g}^{-1} \mathrm{FW}\right)$ & $0.97 \pm 0.05 b$ & $0.58 \pm 0.02 \mathrm{~d}$ & $1.12 \pm 0.04 \mathrm{a}$ & $0.83 \pm 0.03 \mathrm{c}$ \\
\hline chl-b content ( $\mathrm{mg} \mathrm{g}^{-1} \mathrm{FW}$ & $0.78 \pm 0.03 \mathrm{ab}$ & $0.36 \pm 0.01 \mathrm{~d}$ & $0.85 \pm 0.02 \mathrm{a}$ & $0.62 \pm 0.02 \mathrm{c}$ \\
\hline $\mathrm{Chl}(\mathrm{a}+\mathrm{b})$ content $\left(\mathrm{mg} \mathrm{g}^{-1} \mathrm{FW}\right)$ & $1.75 \pm 0.06 \mathrm{~b}$ & $0.94 \pm 0.03 \mathrm{~d}$ & $1.97 \pm 0.06 \mathrm{a}$ & $1.45 \pm 0.04 \mathrm{c}$ \\
\hline
\end{tabular}

The result suggested that $0.1 \mathrm{~m} M \mathrm{CeCl}_{3}$ application increased the content of chl-b more significantly than the other two indicators of seedlings under salt stress. Furthermore, under normal condition $0.1 \mathrm{~m} M \mathrm{CeCl}_{3}$ application notably enhanced chl-a, chl-b and total chlorophyll contents of $H$. tuberosus.

\section{ROS Accumulation and Lipid Peroxide Level}

The contents of $\mathrm{H}_{2} \mathrm{O}_{2}, \mathrm{O}_{2} \cdot{ }^{-}$and MDA in $H$. tuberosus seedlings under various conditions were shown in Fig. 1. It can be seen that $\mathrm{H}_{2} \mathrm{O}_{2}, \mathrm{O}_{2}{ }^{-}$and MDA contents of $\mathrm{H}$. tuberosus seedlings increased in response to $150 \mathrm{mM} \mathrm{NaCl}$ stress compared to the control. $\mathrm{H}_{2} \mathrm{O}_{2}$ contents of the seedlings treated by $\mathrm{NaCl}$ were significantly increased and being $49.3 \%$ higher than that of control. However, $0.1 \mathrm{mM}$ $\mathrm{CeCl}_{3}$ addition significantly diminished $\mathrm{H}_{2} \mathrm{O}_{2}$ content (about 23.2\%) in $\mathrm{NaCl}$ treatment. $\mathrm{NaCl}$ treatment brought about a sharp $\mathrm{O}_{2} \cdot{ }^{-}$accumulation up to approximately double of the control but inhibited about $15.9 \%$ by $\mathrm{CeCl}_{3}$ addition. $\mathrm{NaCl}$ stress caused a $60.7 \%$ increase in the MDA content of seedlings in controls. However, at the same $\mathrm{NaCl}$ concentration $0.1 \quad \mathrm{~m} M \quad \mathrm{CeCl}_{3}$ application significantly reduced the seedlings MDA content (about 21.9\%) compared with those of $\mathrm{NaCl}$ treatment. Under normal condition $\mathrm{CeCl}_{3}$ application showed no significant increases $\mathrm{H}_{2} \mathrm{O}_{2}, \mathrm{O}_{2} .^{-}$and MDA contents of the seedlings.

\section{Antioxidant Defense}

The effects of different treatments on SOD, CAT and POD activities are presented in Fig. 2. The activity of SOD in leaves of $H$. tuberosus seedlings treated by $150 \mathrm{mM} \mathrm{NaCl}$ was significantly increased compared with the control. The application of $0.1 \mathrm{mM} \mathrm{CeCl} 3$ to $\mathrm{NaCl}$-treatment solutions increased the activities of SOD by $39.7 \%$ compared with the plants treated with $\mathrm{NaCl}$. CAT activity in leaves of NaCl-treatment $H$. tuberosus seedlings was relatively low compared with the control. However, addition of $0.1 \mathrm{~m} M$
$\mathrm{CeCl}_{3}$ to $\mathrm{NaCl}$-treatment solutions stimulated the activity of CAT (about 31.9\%) in the leaves. The activity of POD in $\mathrm{NaCl}$-stressed leaves, significantly increased compared with the control. Similar to the effect on the activity of SOD the addition of $0.1 \mathrm{~m} M \mathrm{CeCl}_{3}$ to $\mathrm{NaCl}$-treatment solutions enhanced POD activity by $23.9 \%$ in leaves of $\mathrm{NaCl}$-treatment plants. The result indicated that treatment with $\mathrm{CeCl}_{3}(0.1 \mathrm{mM})$ increased SOD activity more significantly than CAT and POD activities of seedlings under salt stress. Under normal conditions the application of $0.1 \mathrm{mM} \mathrm{CeCl} l_{3}$ seemed to be no notable effects on SOD activity but obviously enhanced CAT and POD activities of the seedlings compared to the control.

\section{Discussion}

The growth status of plant can be reflected by growth indices such as the plant height, fresh weight (leaves, stems and roots) and dry weight of plant (Ni et al., 1996). In the present study, treatment with $\mathrm{NaCl}(150 \mathrm{mM})$ significantly inhibited the plant height, fresh weight and dry weight of $H$. tuberosus seedlings. A growth reduction would be potential energy cost for salinity combat (Munns and Tester, 2008). The results from the present work indicate $0.1 \mathrm{~m} M \mathrm{CeCl}_{3}$ application significantly improved the growth of seedlings grown under salt stress. It has been reported that $0.1 \mathrm{~m} M$ $\mathrm{CeCl}_{3}$ can alleviate the reduction in growth under adverse conditions was related to improving water status and photosynthesis in soybean seedlings (Mao et al., 2012). We speculate that $0.1 \mathrm{mM} \mathrm{CeCl}$ alleviates the water stress and increases the photosynthesis might be associated with its effect on growth of plants in the present stress conditions. It has been reported that treatments with different $\mathrm{Ce}^{3+}$ affected the uptake of $\mathrm{K}, \mathrm{Mg}, \mathrm{Ca}, \mathrm{Na}, \mathrm{Fe}, \mathrm{Mn}, \mathrm{Zn}, \mathrm{Cu}$ and Mo in the shoots and roots (Liu et al., 2012). Our results suggested that $\mathrm{CeCl}_{3}$ treatment promoted the growth of $H$. tuberosus seedlings, which might be attributed to $\mathrm{CeCl}_{3}$ application improving the uptake of mineral nutrition elements. 


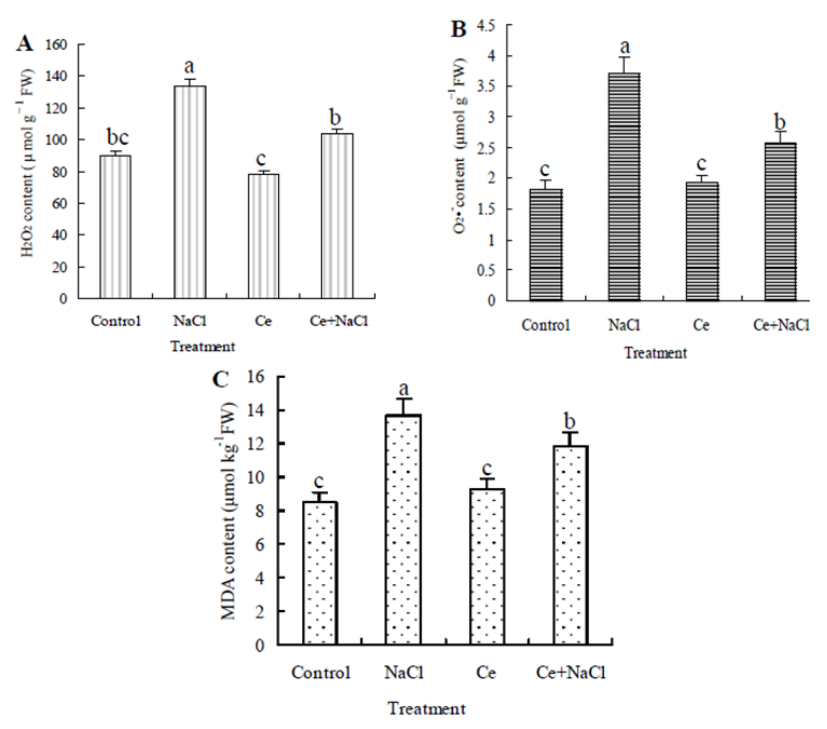

Fig. 1: Effect of $\mathrm{CeCl}_{3}$ and $\mathrm{NaCl}$ on $\mathrm{H}_{2} \mathrm{O}_{2}(\mathrm{~A}), \mathrm{O}_{2}{ }_{2}^{-}$(B) and MDA (C) content in $H$. tuberosus. Each value represents the mean $\pm \mathrm{SD}, \mathrm{n}=3$. Different letters within each graph indicate statistically significant differences at $P<0.05$ using Duncan's Multiple Range Test (DMRT)

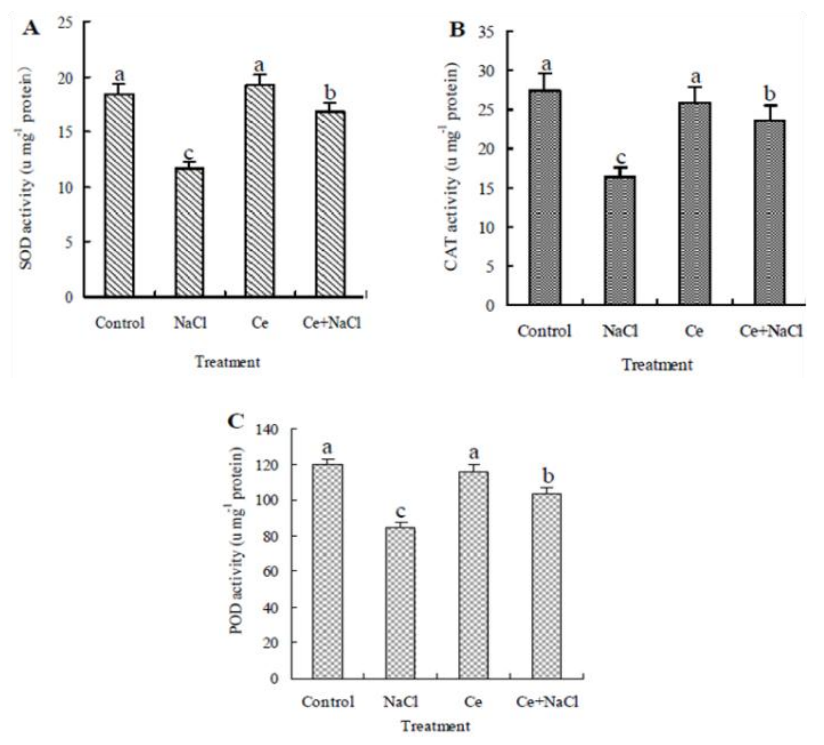

Fig. 2: Effect of $\mathrm{CeCl}_{3}$ and $\mathrm{NaCl}$ on $\mathrm{SOD}(\mathrm{A}), \mathrm{CAT}(\mathrm{B})$ and POD (C) activities of $H$. tuberosus. Each value represents the mean $\pm S D, n=3$. Different letters within each graph indicate statistically significant differences at $P<0.05$ using Duncan's Multiple Range Test (DMRT)

Chlorophyll content is an important index reflecting physiological state of leaf, corresponding well with photosynthetic capability (Xie et al., 2013). In green plants, oxidative stress is usually monitored by measuring chlorophyll content (MacFarlane, 2003; Liu et al., 2012). Our study showed that the content of chl-a, chl-b and total chlorophyll was significantly decreased when treatment with $\mathrm{NaCl}(150 \mathrm{mM})$, which was in consistent with the previous findings (Huang et al., 2012). It has been reported that the effect of $\mathrm{Ce}^{3+}$ on the chlorophyll contents was that $\mathrm{Ce}^{3+}$ increased the absorption of nitrogen and phosphorus (Liao et al., 1994; Hong et al., 2002; Song et al., 2003; Yin et al., 2009). In this study, the addition of $0.1 \mathrm{mM} \mathrm{CeCl} \mathrm{Cl}_{3}$ could remarkably increase chl-a, chl-b and total chlorophyll contents in $H$. tuberosus seedling under salt stress or normal conditions. The most likely reason can be attributed to the absorption of nitrogen and phosphorus and subsequent induction of the synthesis of precursors of chlorophyll by $\mathrm{CeCl}_{3}$.

It is clear that high salinity produces oxidative stress and increases reactive oxygen species (ROS) in plants, such as $\mathrm{H}_{2} \mathrm{O}_{2}$ and $\mathrm{O}_{2} .^{-}$(Tanou et al., 2009). Overproduction of ROS might cause adverse effect that lead to extensive lipid peroxidation as indicated by higher accumulation of MDA in chloroplasts of plants (Gossett et al., 1994). In this study, high salinity significantly increases $\mathrm{H}_{2} \mathrm{O}_{2}, \mathrm{O}_{2}{ }^{-}$and MDA content in H. tuberosus seedlings, implying that salt stress caused increased ROS production. Previous studies have found that REEs could protect plants against oxidative injury (Wang et al., 2011b; Xie et al., 2013). The reduction of $\mathrm{Ce}^{4+}$ to $\mathrm{Ce}^{3+}$ is thought to generate superoxide anions. It is postulated that $\mathrm{Ce}^{3+}$ can react with hydroxyl radicals and act as an antioxidant (Park et al., 2008; Celardo et al., 2011). In this experiment, $0.1 \mathrm{~m} M \mathrm{CeCl}_{3}$ decreased production of $\mathrm{H}_{2} \mathrm{O}_{2}, \mathrm{O}_{2}{ }^{-}$and accumulation of MDA induced by salt stress, suggesting that $\mathrm{CeCl}_{3}$ could directly remove ROS and protect plasma membrane lipid against oxidative damage.

In order to minimize oxidative damage in adverse environments plant cell has developed the antioxidant defense systems including antioxidative enzymes such as SOD, CAT and POD and antioxidant compounds (Mittler, 2002). SOD is the first line of defense which converts $\mathrm{O}_{2}{ }^{-}$ radicals into $\mathrm{O}_{2}$ and $\mathrm{H}_{2} \mathrm{O}_{2} . \mathrm{H}_{2} \mathrm{O}_{2}$ is toxic and must be eliminated in subsequent reactions. In plant, $\mathrm{CAT}$ and POD played important roles to scavenge $\mathrm{H}_{2} \mathrm{O}_{2}$ from cells. CAT eliminates $\mathrm{H}_{2} \mathrm{O}_{2}$ by breaking it down directly to form $\mathrm{O}_{2}$ and water. POD catalyzes $\mathrm{H}_{2} \mathrm{O}_{2}$-dependent oxidation of substrate (Zhao et al., 2008). In this paper, the activities of SOD, CAT and POD were significantly inhibited under salt stress, implying that exposure to high salinity resulted in an imbalance between ROS and their removal in $H$. tuberosus seedlings. Previous studies have shown that REEs could affect the activities of many antioxidative enzymes and antioxidant compounds in plants. It was reported that addition with $\mathrm{LaCl}_{3}$ increased the activities of SOD, CAT, glutathione reductase (GR) and ascorbate peroxidase (APOX) in Saussurea involucrata under salt stress (Xu et al., 2008). Wang et al. (2011b) found that the treatments of $\mathrm{LaCl}_{3}, \mathrm{CeCl}_{3}$ and $\mathrm{NdCl}_{3}$ significantly increased the activities of antioxidative enzyme in maize seedling under cold stress. 
In this experiment, compared with $\mathrm{NaCl}$ treatment, addition of $\mathrm{CeCl}_{3}$ could significantly increase the activities of SOD, CAT and POD in seedling exposed to salt stress implying that $0.1 \mathrm{mM} \mathrm{CeCl}{ }_{3}$ could increase the antioxidant defense abilities and alleviate the salt-induced oxidative damage of H. tuberosus.

\section{Conclusion}

Exogenous supply of $0.1 \mathrm{~m} M \mathrm{CeCl}_{3}$ could significantly promote the growth of $H$. tuberosus, increase leaf chlorophyll content, alleviate the oxidative damage and protect the antioxidant system from damage under salt stress. Further research should be strengthened for elucidating $\mathrm{CeCl}_{3}$ induced changes at molecular and cellular level. Moreover, the safety of $\mathrm{Ce}^{3+}$ should be investigated in detail with in-depth studies on the effects of $\mathrm{Ce}^{3+}$ on cultivated $H$. tuberosus.

\section{Acknowledgements}

Authors would like to thank Science and Technology Department of Shandong Province (2010GSF10208) for financial support.

\section{References}

Ashraf, M., 2009. Biotechnological approach of improving plant salt tolerance using antioxidants as markers. Biotech. Adv., 27: 84-93

Ashraf, M. and Q. Ali, 2008. Relative membrane permeability andactivities of some antioxidant enzymes as the key determinants of salt tolerance in canola (Brassica napus L.). Environ. Exp. Bot., 63: 26-273

Beauchamp, C. and I. Fridovich, 1971. Superoxide dismutase: Improved assays and assay applicable to acrylamide gels. Anal. Biochem., 44: 276-286

Buege, J.A. and S.D. Aust, 1978. Microsomal lipid peroxidation. Meth. Enzymol., 52: 302-310

Celardo, I., M.D. Nicola, C. Mandoli, J.Z. Pedersen, E. Traversa and L. Ghibelli, 2011. $\mathrm{Ce}^{3+}$ ions determine redox-dependent anti-apoptotic effect of cerium oxide nanoparticles. ACS. Nano., 5: 4537-4549

Durner, J. and D.F. Klessing, 1996. Salicylic acid is a modulator of tobacco and mammalian catalases. J. Biol. Chem., 271: 28492-28502

Elstner, E.F. and A. Heupel, 1976. Inhibition of nitrite formation from hydroxylammonium chloride: a simple assay for superoxide dismutase. Anal. Biochem., 70: 616-620

Gossett, D.R., E.P. Millhollon and M.C. Lucas, 1994. Antioxidant response to $\mathrm{NaCl}$ stress in salt tolerant and salt sensitive cultivars of cotton. Crop. Sci., 34: 706-714

Hammerschmidt, R., E.M. Nuckles and J. Kuc, 1982. Association of enhanced peroxidase-activity with induced systemic resistance of cucumber to colletotrichum-lagenarium. Physiol. Plant. Pathol., 20:73-76

Hong, F.S., L. Wang, X.X. Meng, Z. Wei and G.W. Zhao, 2002. The effect of cerium (III) on the chlorophyll formation in spinach. Biol. Trace. Elem. Res., 89: 263-276

Huang, Z.R., X.H. Long, L. Wang, J. Kang and Z.P. Liu, 2012. Growth, photosynthesis and $\mathrm{H}^{+}$-ATPase activity in two Jerusalem artichoke varieties under $\mathrm{NaCl}$-induced stress. Process Biochem., 47: 591-596

Kasim, W.A., K.M. Saad-Allah and M. Hamouda, 2016. Seed priming with extracts of two seaweeds alleviates the physiological and molecular impacts of salinity stress on radish (Raphanus sativus). Int. J. Agric. Biol., 18: 653-660
Liao, T.J., Y. Huang and L.B. Su, 1994. Study of rare earths on yields, qualities and physiological effect of spinach. Rare. Earths (in Chin.), 15: 26-29

Liu, D.W., X. Wang, Y.S. Lin, Z.W. Chen., H.Z. Xu and L. Wang, 2012. The effects of cerium on the growth and some antioxidant metabolisms in rice seedlings. Environ. Sci. Pollut. Res., 19: 3282-3291

Long, X.H., S. Mehta and Z.P. Liu, 2008. Effect of $\mathrm{NO}^{3-}-\mathrm{N}$ enrichment on seawater stress tolerance of Jerusalem artichoke (Helianthus tuberosus L.). Pedosphere, 18: 113-123

MacFarlane, G.R., 2003. Chlorophyll a fluorescence as a potential biomarker of zinc stress in the grey mangrove, Avicennia marina. Bull. Environ. Contam. Toxicol., 70: 90-96

Mao, C.X., M.M. Chen, L. Wang, H. Zou, C.J. Liang, L.H. Wang and Q. Zhou, 2012. Protective effect of cerium ion against ultraviolet B radiation-induced water stress in soybean seedlings. Biol. Trace. Elem. Res., 146: 381-387

Mittler, R., 2002. Oxidative stress, antioxidants and stress tolerance. Tre. Plant. Sci., 7: 405-410

Monti, A., M.T. Amaducci and G. Venturi, 2005. Growth response, leaf gas exchange and fructans accumulation of Jerusalem artichoke (Helianthus tuberosus L.) as affected by different water regimes. Eur. J. Agron., 23: 136-145

Munns, R. and M. Tester, 2008. Mechanisms of salinity tolerance. Annu. Rev. Plant. Biol., 59: 651-681

Ni, H.W., S.Y. Zang and Y.K. Gao, 1996. Study on seasonal dynamics of above ground biomass and growth rate of Deyeuxia An-gustifolia population in marsh meadow on Sanjiang plain. Bull. Bot. Res., 16: 489-495

Nounjan, N., P.T. Nghia and P. Theerakulpisut, 2012. Exogenous proline and trehalose promote recovery of rice seedlings from salt-stress and differentially modulate antioxidant enzymes and expression of related genes. J. Plant. Physiol., 169: 596-604

Park, E.J., J. Choi, Y.K. Park and K. Park, 2008. Oxidative stress induced by cerium oxide nanoparticles in cultured BEAS-2B cells. Toxicology, 245: 90-100

Sergio, L., A. De, V. Paola, M. Cantore, N. Pieralice, A. Cascarano, V.V. Bianco and D. Di Venere, 2012. Effect of salt stress on growth parameters, enzymatic antioxidant system, and lipid peroxidation in wild chicory (Cichorium intybus L.). Acta. Physiol. Plant., 34: 2349-2358

Song, W.P., F.S. Hong, Z.G. Wan, Y.Z. Zhou, F.G. Gu, H.G. Xu, M.L. Yu, Y.H. Chang, M.Z. Zhao and J.L. Su, 2003. Effects of cerium on nitrogen metabolism of peach plantlet in vitro. Biol. Trace. Elem. Res., 95: 259-268

Shabala, S. and T.A. Cuin, 2008. Potassium transport and plant salt tolerance. Physiol. Plant., 133: 651-669

Tanou, G., A. Molassiotis and G. Diamantidis, 2009. Induction of reactive oxygen species and necrotic death-like destruction in strawberry leaves by salinity. Environ. Exp. Bot., 65: 270-278

Tabassam, T., S. Kanwal, S.M.S. Naqvi, A. Ali, B.U.Z. Zaman and M.E. Akhter, 2016. Effect of manganese application on PS-II activity in rice under saline conditions. Int. J. Agric. Biol., 18: 837-843

Wang, L.H., X.H. Huang and Q. Zhou, 2009. Protective effect of rare earth against oxidative stress under ultraviolet-B radiation. Biol. Trace. Elem, Res., 12: 82-93

Wang, Y.J., H.B. Jin, S.H. Deng, Y. Chen and Y. Yu, 2011a. Effects of neodymium on growth and physiological characteristics of Microcystis aeruginosa. J. Rare. Earth., 29: 388-395

Wang, Y.J., J. Li, Y. Lü, H.B. Jin, S.H. Deng and Y.M. Zeng, 2012. Effects of cerium on growth and physiological characteristics of Anabaena flosaquae. J. Rare. Earths., 30: 1287-1292

Wang, Y., M. Zhou, X.L. Gong, C. Liu, M.M. Hong, L. Wang and F.S. Hong, 2011b. Influence of lanthanides on the antioxidative defense system in maize seedlings under cold stress. Biol. Trace. Elem. Res., 142: 8 19-830

Wellburn, A.R., 1994. The spectral determination of chlorophylls a and b, as well as total carotenoids using various solvents with spectrophotometers of different resolution. J. Plant. Physiol., 144: 307-313 
Wu, X.X., J. He, J.L. Chen, S.J. Yang and D.S. Zha, 2014. Alleviation of exogenous 6-benzyladenine on two genotypes of eggplant (Solanum melongena Mill.) growth under salt stress. Protoplasma, 251: 169-176

Xie, Y.F., X.L. Cai, W.L. Liu, G.S. Tao, Q. Chen and Q. Zhang, 2013. Effects of lanthanum nitrate on growth and chlorophyll fluorescence characteristics of Alternanthera philoxeroides under perchlorate stress. J. Rare. Earth., 31: 823-829

Xu, C.M., B. Zhao, X.D. Wang and Y.C. Wang, 2008 Lanthanum relieves salinity-induced oxidative stress in Saussurea involucrata. Biol. Plant., 51: 567-570

Xue, Y.F. and Z.P. Liu, 2008. Antioxidant enzymes and physiological characteristics in two Jerusalem artichoke cultivars under salt stress. Russ. J. Plant. Physiol., 55: 776-781
Yin, S.T., Y.G. Ze, C. Liu, N. Li, M. Zhou, Y.M. Duan and F.S. Hong, 2009. Cerium relieves the inhibition of nitrogen metabolism of spinach caused by magnesium deficiency. Biol. Trace. Element. Res., 132: 247-258

Zhang, C., Q. Li, M. Zhang, N. Zhang and M. Li, 2013. Effects of rare earth elements on growth and metabolism of medicinal plants. Acta. Pharm. Sin. B., 3: 20-24

Zhao, J., G.X. Shi and Q.H. Yuan, 2008. Polyamines content and physiological and biochemical responses to ladder concentration of nickel stress in Hydrocharis dubia (B1.) backer leaves. BioMetals, 21: $665-674$

(Received 24 May 2017; Accepted 23 June 2017) 